\title{
Unusual endobronchial extension of bronchial carcinoma treated by YAG laser and surgery
}

\author{
M TORRE, B BARBIERI, F DONATELLI, M RAVINI, GF RIZZATO, PA BELLONI \\ From the Thoracic Surgery Division and the Division of Medicine, Niguarda Hospital, Milan, Italy
}

Despite the recent advances in diagnostic techniques, most lung cancers are at an advanced stage when detected and are considered inoperable. We report a case in which neodymium yttrium-aluminium-garnet (Nd YAG) laser phototherapy permitted limited lung resection in a patient whose lung cancer had been diagnosed as inoperable.

\section{Case report}

A 54 year old man was admitted to our division as an emergency suffering from respiratory failure and haemoptysis. Chest radiographs and tomograms performed at another hospital showed collapse of the right lung (fig 1). The patient was given oxygen therapy and high dose steroid treatment ( $1.5 \mathrm{~g}$ of hydrocortisone daily) for 15 days. On his admission to hospital, blood gas analysis showed an arterial oxygen tension $\left(\mathrm{PaO}_{2}\right)$ of $54 \mathrm{~mm} \mathrm{Hg}(7.2 \mathrm{kPa})$, a carbon dioxide tension $\left(\mathrm{PaCO}_{2}\right)$ of $34 \mathrm{~mm} \mathrm{Hg}(4.5 \mathrm{kPa})$, and $\mathrm{pH}$ $7 \cdot 34$. The respiratory rate was $36-40$ breaths/minute. He was considered to be unable to perform spirometric tests and was excluded from surgical treatment because of his poor respiratory function and the extent of the tumour.

An emergency fibreoptic bronchoscopy was performed and a polypoid intraluminal tumour completely obstructing the orifice of the right main bronchus was detected (histological examination later showed this to be a squamous cell carcinoma).

At the same session, after informed consent by our patient, YAG laser phototherapy was carried out to give immediate relief from the obstruction. The fibre of the YAG laser was introduced through the operative channel of a fibreoptic bronchoscope (Olympus BF1T10) and treatment was begun with the patient still under local anaesthesia with $4 \%$ lignocaine. The first treatment lasted 50 minutes; 6570 joules were delivered in a 60 watt power setting in short pulses (lasting less than one second). As a result the mainstem bronchus and the right upper lobe bronchus were partially reopened. Immediately the patient's clinical condition improved and his respiratory distress diminished. The chest radiograph showed the partial reaeration of the lung; arterial oxygen and carbon dioxide tensions were $66 \mathrm{~mm} \mathrm{Hg}$ and $42 \mathrm{~mm} \mathrm{Hg}(8.8$ and $5.6 \mathrm{kPa})$ respectively without further supplementary oxygen.

Three more YAG laser treatments using the same tech-

Address for reprint requests: Dr M Torre, Via Teodosio 55, 20131 Milan, Italy.

Accepted 30 January 1987 nique were necessary to reopen the right mainstem bronchus completely. A total of $25500 \mathrm{~J}$ were delivered. Finally, the primary focus of the tumour was detected in the B6 bronchus and its extension showed a cranial polypoid tumour. Endoscopy and tomography showed no evidence of neoplastic infiltration of the main or right upper lobe bronchus (fig 2). Examination of many biopsy samples and brushings obtained from different levels of the bronchial wall excluded invasion of the mucosa by cancer cells. After laser treatment removal of the tumour by lower and middle lobectomy appeared possible. Thirty days after the first laser treatment the patient underwent surgery.

At thoracotomy a small tumour (diameter $1.5 \mathrm{~cm}$ ) was detected originating from the apex of the right lower lobe and also affecting the middle lobe. A right lower and middle lobectomy was performed. The postoperative course was uneventful and the patient was discharged nine days after surgery.

The histological examination of the resected specimen confirmed that there was a squamous cell carcinoma with metastases at one hilar node but without mediastinal node

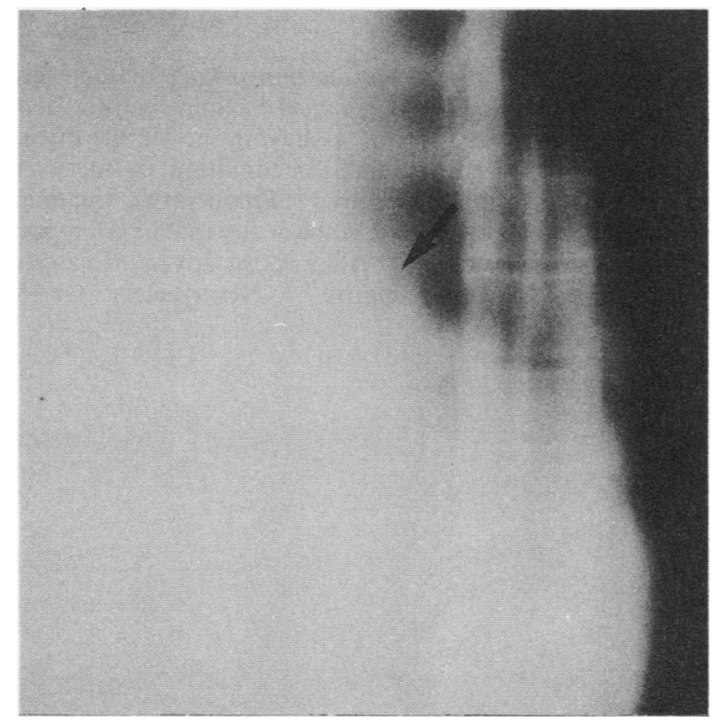

Fig 1 Anteroposterior mediastinal tomogram: the tumour is obstructing the right main bronchus and bulging into the trachea (arrow). 
900

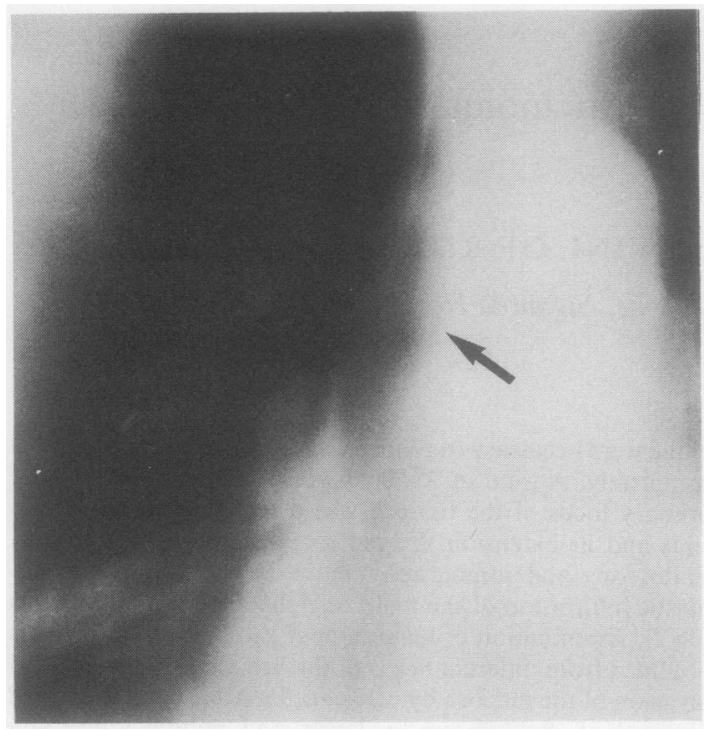

Fig 2 Anteroposterior mediastinal tomogram showing the reopened right mainstem bronchus (arrow) and upper lobe bronchus after YAG laser phototherapy.

metastases. No residual tumour was detected on the bronchial stump.

Twelve months after his first YAG laser phototherapy the patient is alive and doing well, showing no evidence of any recurrence.

\section{Discussion}

Surgical resection still offers the best chance of long term survival in patients with lung cancer. ${ }^{12}$ Some workers have shown that patients assessed as having inoperable disease can be converted to an operable condition by means of radiotherapy or chemotherapy. ${ }^{34}$ Preoperative treatment with the argon Dy laser has also been described. ${ }^{5}$ All reports agree that the role of the YAG laser in advanced cases of lung cancer is only palliative. ${ }^{67}$ Nevertheless, George
Torre, Barbieri, Donatelli, Ravini, Rizzato, Bellon寻 recently described the case of a patient with tracheal cancer in whom YAG laser therapy facilitated elective surgery. ${ }^{8}$

To our knowledge, no case has been reported in which a $\frac{\bar{\sigma}}{\bar{s}}$ patient originally considered inoperable because of the $\frac{5}{\partial}$ extension of the tumour to the mainstem bronchus has $\Omega$ undergone surgery after the reopening of the bronchus. Cases like the one described here are rare but serve as $a_{-}$ reminder that tumours originating from the lobar bronchus. may show a polypoid cranial development along the main- $\vec{\overrightarrow{ }}$ stem bronchus.

In these cases, in which pneumonectomy appears necessary, the use of laser treatment may sometimes allow the $x$ surgeon to carry out a more limited resection. A prerequisite $\vec{N}$ for success is the polypoid development of the tumour with-out invasion of the bronchial mucosa. For this reason, $\overrightarrow{-}$ numerous biopsy samples and brushings have to be obtainedo to ascertain that the bronchial stump has not been invaded by tumour.

We conclude that YAG laser phototherapy not only has apalliative role but may occasionally be of value in the pre- $Z$ operative treatment of carcinoma of the bronchus.

\section{References}

1 Martini N, Flehinger BY, Zaman MB, Beattie EJ Jr. Prospective $\vec{C}$ study of $\mathbf{4 4 5}$ lung carcinomas with mediastinal lymph nodeœ metastasis. J Thorac Cardiovasc Surg 1980;80:390-9.

2 Mintz BY, Tunrim S, Alexander S, Yang WC, Shanzer S.C Entracranial metastasis in the initial staging of bronchopenic carcinoma. Chest 1984;86:850-3.

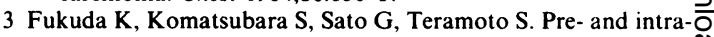
operative chemotherapy using FT 207 suppositories-with special reference to lung cancer [in Japanese]. Gan To Kagaku Ryoho.

4 Scherman DM, Weichselbaum RR. The use of preoperative radi- $\overrightarrow{\hat{O}}$ ation therapy in the treatment of lung carcinoma. Cancer 3 Treat Rep 1981;1:63-73.

5 Kato $\mathrm{H}$, Konaka C, Ono J, et al. Preoperative laser photo= dynamic therapy in combination with operation in lung cancer. J Thorac Cardiovasc Surg 1985;90:420-9.

6 Hetzel MR, Nixon C, Edmonstone W, et al. Laser therapy in 1000 tracheobronchial tumors. Thorax 1985;40:341-5.

7 Wolfe WG, Sabiston DC Jr. Management of benign and malignant lesions of the trachea and bronchi with the neodymium-5 yttrium-aluminium garnet laser. $J$ Thorac Cardiovasc Surg. 1986;91:40-5.

8 George PYM, Garret CPO, Goldstraw P, Hetzel MR, Ramsay AD. Resuscitative laser photoresection of a tracheal tumour before elective surgery. Thorax 1986;41:812-3. 